\title{
Zur schweren Sexualdelinquenz vor den böhmischen Stadtgerichten im 16. und beginnenden 17. Jahrhundert
}

\begin{abstract}
Heavy sexual delinquency before Czech town courts of justice in 16 th and early 17 th centuries

The article deals with heavy sexual criminality before town courts of justice in the Kingdom of Bohemia in the course of the 16th and early 17th centuries. For the purpose of this study, this includes sexual delicts and delicts against marriage punishable by the death penalty according to the law of the period studied. This penalty was applied to cases of rape (kidnapping of a woman) (raptus), violation, violation of a child (stuprum violentum infantis), resp. sexual abuse, bigamy, incest, sodomy in the form of sexual contact with an animal, sodomy in the form of homosexuality and other forms of it (transsexuality, transvestism, exhibitionism). Amongst the several thousand recorded criminal cases decided by the the investigated courts of justice during the period studied, such heavy sexual delicts are found only in a few dozen cases. In relatively higher numbers appear only bigamy, sexual contact with an animal and violation. Other heavy sexual delicts are recorded only sporadically, or in isolated cases.
\end{abstract}

Keywords: 16th century - courts of justice - Kingdom of Bohemia - sexual criminality - town

Als schwere Sexualdelikte kann man (für den Zweck des vorliegenden Beitrags) jene Sexualstraftaten und Straftaten gegen die Ehe einstufen, für die es nach dem zeitgenössischen Strafrecht nicht nur möglich war, die qualifizierte Todesstrafe aufzuerlegen, sondern bei denen diese Strafe bei den böhmischen Stadtgerichten im 16. und am Anfang des 17. Jahrhunderts auch in der Praxis regelmäßig auferlegt und vollzogen wurde. Diese Feststellung verbirgt in sich trotz scheinbarer Einfachheit einige faktische und methodische Probleme.

Die Sittendelikte, d.h. vor allem Sexualdelikte und Delikte gegen die Ehe, beinhalteten im frühneuzeitlichen Böhmen mehrere Typen von schwerwiegenden kriminellen Handlungen. Konkret werden in diese Deliktgruppe einbezogen Bigamie, Ehebruch, Entführung (oder Weglocken) einer Frau (Ehegattin, Witwe, unverhei- ratetes Mädchen), Unzucht (stuprum), Konkubinat, Vergewaltigung (Notzucht), einschließlich der Vergewaltigung eines Kindes und sexuellen Kindesmissbrauchs, Inzest (Blutschande), Sodomie (in Gestalt homosexueller Beziehungen bzw. anderer Typen sexuellen Verhaltens, z.B. Geschlechtsverkehr mit Tieren), Prostitution (fornicatio) und Kuppelei (lenonicium). ${ }^{1}$ Aus diesen so definierten Straftaten gegen die Sitte lassen sich als leicht diejenigen nennen, auf die nach dem damaligen böhmischen städtischen Strafrecht nicht die Todesstrafe stand (Prostitution und Kuppelei²), oder es war möglich, für sie nach dem zeitgenössischen geltenden Recht die

\footnotetext{
${ }^{1}$ FRANCEK, Zločin a sex 92-117 und 124-130; DERS., Já jsem se dopustila 38-52; MALÝ, Trestní právo 231-246. ${ }^{2}$ FRANCEK, Zločin a sex 124-130; DERS., Já jsem se dopustila 49f.; MALÝ, Trestní právo 246.
} 
Kapitalstrafe aufzuerlegen, die aber in der Praxis im 16. Jahrhundert entweder fast nicht mehr (Unzucht, ${ }^{3}$ Konkubinat ${ }^{4}$ ) oder nur in schwerwiegenderen Fällen (Ehebruch ${ }^{5}$ ) zur Anwendung kam.

Die restlichen Sexualdelikte und Delikte gegen die Ehe, also Entführung, Vergewaltigung (Notzucht), Vergewaltigung eines Kindes, bzw. sexueller Missbrauch, Bigamie (Doppelehe), Inzest (Blutschande) und verschiedene Formen der Sodomie (insbesondere männliche Homosexualität und Geschlechtsverkehr mit einem Tier), ${ }^{6}$ lassen sich dann entsprechend oben genannter Bestimmung als schwere Sitten-, bzw. sexuelle Straftaten bezeichnen.

Ein grundsätzliches methodisches Problem beim Studium schwerer Sexualdelikte bei böhmischen städtischen Gerichten in der Zeit vor der Schlacht am Weißen Berg (1620) besteht darin, dass diese Straftaten nur relativ sporadischen vorkamen. Einige von diesen Delikten kann man in den böhmischen Quellen des 16. und des Anfangs des 17. Jahrhunderts sogar so selten antreffen, dass sie sich fast der Möglichkeit einer zweckmäßigen systematischen Erforschung entziehen, weil der Forscher in dem erhaltenen Schrifttum gerichtlicher Provenienz und in anderen Quellen nur ausnahmsweise und sporadisch auf sie zu stoßen vermag. Ihr Studium setzt also in der Regel vorangehende umfangreiche Kenntnis der in Frage kommenden relevanten Quellen voraus.

Die grundlegende Quelle der Erkenntnis der städtischen Kriminal- bzw. Halsgerichtsbarkeit im Böhmen vor der Schlacht am Weißen Berge

\footnotetext{
${ }^{3}$ FRANCEK, Zločin a sex 104-110; DERS., Já jsem se dopustila 42-44; MALÝ, Trestní právo 241-244.

${ }^{4}$ FRANCEK, Zločin a sex 92; DERS., Já jsem se dopustila 38.

${ }^{5}$ FRANCEK, Zločin a sex 97-102; MALÝ, Trestní právo 232-237.

${ }^{6}$ FRANCEK, Zločin a sex 92-96 und 115-117; DERS., Já jsem se dopustila 44-47; MALÝ, Trestní právo 232-246.
}

stellen die sogenannten Schwarzen (Pech-, Blut-) Bücher dar. Den Hauptteil der Eintragungen in den böhmischen Schwarzen Büchern stellen bis zur Mitte des 17. Jahrhunderts in der Regel die Folteraussagen der verhörten Verbrecher dar. ${ }^{7}$ Obwohl in Böhmen zu Anfang des 17. Jahrhunderts mehr als 350 königliche und patrimoniale Städte und patrimoniale Marktflecken berechtigt waren, die Halsgerichtsbarkeit auszuüben, ${ }^{8}$ haben sich aus ganz Böhmen aus der Zeit vor der Schlacht am Weißen Berge nur annähernd zwei Dutzend Schwarze Bücher erhalten, deren Mehrzahl darüber hinaus nicht das 16. und den Anfang des 17. Jahrhunderts in extenso umfasst, sondern höchstens einige Jahrzehnte. ${ }^{9}$ Die anderen Quellen gerichtlicher Provenienz aus dem 16. Jahrhundert und dem Anfang des 17. Jahrhunderts stellen (bezüglich ihrer Aussagekraft) in ihrer Beziehung zu den Schwarzen Büchern nur komplementäre Quellen dar. Die Angaben der betreffenden Quellen können manchmal durch Nachrichten aus den zeitgenössischen narrativen Texten ergänzt werden.

\section{Entführung}

Die Entführung (raptus) (einer Gattin, Witwe oder eines unverheirateten Mädchens) stellte eine Straftat dar, deren gesetzliche Regelung in der fraglichen Zeit nur das Landesgewohnheitsrecht enthielt. Dieses hielt schon seit Mittelalter die Entführung für ein schwerwiegendes gewalttätiges Delikt. ${ }^{10}$

\footnotetext{
${ }^{7}$ Zur Charakteristik und Übersicht der auf uns gekommenen Schwarzen Bücher aus den Böhmischen Ländern vgl. den Aufsatz: KREUZ, Stav.

${ }^{8}$ Zur Entwicklung des Netzes der Halsgerichte in Böhmen am Ende des Mittelalters und in der Frühen Neuzeit bis jetzt am besten RoUČKA, Poznámky.

${ }^{9}$ KREUZ, Stav 225f., Anm. 36.

${ }^{10}$ MALÝ, Trestní právo 238-241; FRANCEK, Zločin a sex 102-104.
} 
Eine Alternative zur Entführung stellte im städtischen Gewohnheitsrecht und in der städtischen Rechtspraxis das sogenannte "ulouzeni“" dar. Dieser Rechtsbegriff umfasste sowohl die gewalttätige Entführung der Frau als auch ihr freiwilliges Verlassen des Ehemanns oder der Familie (und also auch der Ehebruch), das aber als Folge des Weglockens zustande kam. ${ }^{11}$ Nach dem Rechtsbuch des Meisters Brikcius Kouřimský von Licsko (ca. 1488-1543), das im Jahre 1536 gedruckt wurde und das auf dem berühmten Brünner Rechtsbuch des Schreibers Johann aus den 50er-Jahren des 14. Jahrhunderts beruhte, $^{12}$ sollte ein Mann, der die Frau eines anderen weglockte und durch Zeugenaussagen überführt wurde, auf einen scharfen Pfahl geschlagen werden. Die gleiche Strafe wie für den Täter des Weglockens sollte die Ehegattin treffen, die überführt wurde, dass sie mit dem Betreffenden freiwillig wegging. ${ }^{13}$ Eine besondere Strafe statuierte Brikcius für einen Mann, der ein weniger als zwölf Jahre altes Mädchen oder eine Witwe weggelockt hatte. Ein solcher Täter sollte, falls ergriffen, enthauptet, wenn er geflüchtet wäre, lebenslänglich der Stadt verwiesen werden. ${ }^{14}$ Brikcius' Rechtsbuch sah außerdem auch eine Strafe für eine Frau vor, die sich der Wegschleppung oder Entlockung eines minderjährigen Mannes (das heißt eines Mannes, der jünger als 18 Jahre war) schuldig machte. Die Frau sollte ihres Erbteils verlustig gehen und gemeinsam mit dem betroffenen Knaben aus der Stadt auf

\footnotetext{
${ }^{11}$ MALÝ, Trestní právo 239; FRANCEK, Zločin a sex $102 \mathrm{f}$.

${ }^{12}$ Dazu bisher am besten ČELAKOVSKÝ, O právech městských m. Brikcího 721-736, 757-774, 794-808 und 829-837.

${ }^{13}$ JIREČEK, M. Brikcího 242f. (Kap. XLI., Art. II.) und 246 (Kap. XLI., Art. XI.). Siehe auch Miroslav FLODR, Právní kniha I, 309f. (Art. 483), II, 128f. (Art. 483); DERS., Brněnské městské právo 335 und 477f. Vgl. auch MALÝ, Trestní právo 240, Anm. 206.

${ }^{14}$ JiREČEK, JIREČEK, M. Brikcího 246 (Kap. XLI., Art. XI.).
}

fünfzig Jahre, d. h. praktisch lebenslang, verbannt werden. ${ }^{15}$

Die Begriffe Entführung oder „ulouzení“ kommen dagegen nicht in Koldíns Kodifikation des böhmischen Stadtrechts aus dem Jahre 1579 vor. ${ }^{16}$ Koldín verband die Entführung mit der Vergewaltigung (gewalttätiger Unzucht). ${ }^{17}$ Nach Koldín sei die Entführung als eine Straftat zu beurteilen, wenn das Opfer nachträglich vom Entführer vergewaltigt wurde. Als Entführer wurde hier ein Mensch gehalten, der sich mit Gewalt einer Jungfrau oder Witwe bemächtigte und sie irgendwohin wegschleppte. Der Täter sollte durch Schwert enthauptet werden, wenn es sich aber um eine "leichtfertige“, d. h. unehrliche Person handelte, ${ }^{18}$ sollte die Todesstrafe durch Einflechten in das Rad auferlegt werden. ${ }^{19}$ Eine einzige Bestimmung des Stadtgesetzbuches Koldíns verband auf diese Weise die Entführung mit der Vergewaltigung, und de iure begründete die Strafbarkeit der Entführung nicht nur durch allgemeine Gewalt, sondern leitete sie direkt von der an einer Frau verübten Gewalt (d. h. Vergewaltigung) ab. ${ }^{20}$ Vereinfacht gesagt: Koldín statuiert nicht Strafen für bloße Entführung ohne erfolgte Vergewaltigung der Frau. ${ }^{21}$

\footnotetext{
15 JIREČEK, JIREČEK, M. Brikcího 246f. (Kap. XLI., Art. XII.). Vgl. auch Francek, Zločin a sex 102f. MALÝ, Trestní právo 240, Anm. 207, wies auf ein interessantes Paradox hin, dass der Verfasser des genannten Rechtsbuchs, Brikcius von Licsko, das Opfer der genannten Straftat wurde, nachdem seine zweite Ehefrau geflüchtet war. Dazu eingehend: KREUZ, K projednávání 37.

${ }^{16}$ JIREČEK, Codex juris bohemici; MALÝ, Práva městská Království českého. Vgl. auch MALÝ, Trestní právo 239-241; FRANCEK, Zločin a sex 103f.

17 JIREČEK, Codex juris bohemici 308f. (Art. M. XXXI.).

${ }^{18}$ MALÝ, Práva městská Království českého 278, Art. M. XLII.

${ }^{19}$ JIREČEK, Codex juris bohemici 308 (Art. M. XXXI., Abs. I.).

${ }^{20}$ MALÝ, Trestní právo 240f.; FRANCEK, Zločin a sex $103 f$.

${ }^{21}$ MALÝ, Trestní právo 241.
} 
Ungeachtet dessen, dass weder das Delikt der Entführung noch das Delikt des ulouzení im böhmischen Stadtrecht in der Zeit vor dem Weißen Berge de iure verankert waren, ist es möglich, in der Gerichtspraxis der böhmischen Stadtgerichte im 16. Jahrhundert und zu Anfang des 17. Jahrhunderts (wenn auch meistens nur vereinzelt) Fälle der Entführung einer verheirateten Frau, Jungfrau oder Witwe zu verzeichnen. In diesen Fällen überwiegt deutlich die Weglockung die gewalttätige Entführung. Das häufigste Objekt derartiger Handlungsweise war die verheiratete Frau (Ehegattin).

Überraschenderweise kann man ganze zwölf Fälle von „ulouzení (einer Frau) in den Jahren 1547-1612 aufgrund der Pechbücher in der ostböhmischen patrimonialen Residenzstadt bzw seit 1560 königlicher Kammerstadt Pardubitz [Pardubice] verzeichnen. ${ }^{22}$ In den meisten dieser Fälle stand nichtsdestoweniger "ulouzení im Hintergrund hinter den schwerwiegenderen Halsdelikten, am häufigsten hinter den Fällen von Diebstahl und Ehebruch. ${ }^{23}$ Nur in einem einzigen Fall (1555) figurierte „ulouzení" als ein dominantes Delikt. Obwohl der vor Gericht stehende Knecht beim peinlichen Verhör sich auch des Ehebruchs, einiger Diebstähle, der Vorbereitung eines Meuchelmordes, der Betreibung der Liebesmagie, einschließlich der Vorbereitung der vermeintlichen "Liebesgetränke“ schuldig bekannte, wurde er laut Eintragung nur für eine Weglockung fremder Frau durch Pfählung hingerichtet. ${ }^{24}$ Die verheiratete Geliebte des genannten Knechtes, die von ihrem Mann flüchtete (damit machte sie sich des Ehebruchs schuldig) und ihm auf der Flucht nicht wenige

${ }^{22}$ FrANCEK, Pardubické smolné knihy 104f. (Nr. 65), 163f. (Nr. 112), 164f. (Nr. 114 und 115), 221 (Nr. 195), 233 (Nr. 216), 277f. (Nr. 293), 327f. (Nr. 351), 364 (Nr. 408), 388 (Nr. 436), 479f. (Nr. 505) und 604f. (Nr. 590).

${ }^{23}$ Ebd. 104f. (Nr. 65) 221 (Nr. 195), 277-278 (Nr. 293), 327f. (Nr. 351), 364 (Nr. 408) und 479f. (Nr. 505).

${ }^{24}$ Ebd. 163f. (Nr. 112).
Habseligkeiten und bares Geld entwendete, ereilte die gleiche Strafe, d.h. Durchbohrung durch den Pfahl. ${ }^{25}$ Eine Frau, die nur den Ehebruch, aber nicht die Flucht des genannten Liebespaares meldete und vor Gericht freiwillig, ohne Folter aussagte, wurde zum Tode durch Ertrinken verurteilt. ${ }^{26}$ Aus dem Gesagten ergibt sich, dass das Pardubitzer Gericht bei der Ahndung der "ulouzení" sich relativ strikt entweder an die oben genannte Bestimmung des Rechtsbuchs des Brikcius von Licsko hielt. ${ }^{27}$

In weiteren auf uns gekommenen Schwarzen Büchern aus dem 16. Jahrhundert und dem Anfang des 17. Jahrhunderts kann man „ulouzeni” bzw. Entführung nur sporadisch in einzelnen Fällen registrieren.

\section{Vergewaltigung (Notzucht)}

Das Delikt der Vergewaltigung (stuprum violentum) wurde im böhmischen Stadtrecht durch das Gesetzbuch Koldíns geregelt. ${ }^{28}$ Koldín übernahm dabei die Bestimmung, die man schon im mittelalterlichen böhmischen Landesgewohnheitsrecht vorfindet. ${ }^{29}$ Ein der Vergewaltigung Schuldiger sollte mit dem Schwert bestraft werden. Sollte sich aber eine unehrliche Person der Vergewaltigung schuldig gemacht haben, ${ }^{30}$ sollte sie durch Einflechten in das Rad bestraft sein. ${ }^{31}$ Dieselben Strafen hatte auch der zu erleiden, welcher dem Täter der Vergewaltigung

${ }^{25}$ Ebd. 165 (Nr. 115).

${ }^{26}$ Ebd. 164f. (Nr. 114).

${ }^{27}$ Siehe die oben in Anm. 12 und 13 genannten Titel. ${ }^{28}$ JIREČEK, Codex juris bohemici 308 (Art. M. XXX., Abs. II.). Vgl. die Rechtslage zur Vergewaltigung im Schwabenspiegel von ca. 1275 und in der Peinlichen Halsgerichtsordnung Karls V. 1532: FRITZ, Geschichte der Sexualität 281f.

${ }^{29}$ MALÝ, Trestní právo 244.

${ }^{30}$ MALÝ, Práva městská Království českého 278, Art. M. XLII.

${ }^{31}$ JIREČEK, Codex juris bohemici 308 (Art. M. XXXI., Abs. I.). 
behilflich war. ${ }^{32}$ Es ist darüber hinaus darauf hinzuweisen, dass die oben genannten Strafen das Gesetzbuch Koldíns ausdrücklich nur wegen der Vergewaltigung einer ehrenhaften Frau und darüber hinaus nur einer Jungfrau oder Witwe statuiert. Unerwähnt lässt er also eine eventuelle Vergewaltigung einer verheirateten Frau. ${ }^{33}$ Die an einer unehrlichen Frau ausgeübte sexuelle Gewalt erfüllte in Koldíns Auffassung offensichtlich nicht den Tatbestand des Delikts der Vergewaltigung. ${ }^{34}$ Koldíns Gesetzbuch verpflichtete die Frau, einen unwiderlegbaren Beweis zu liefern, dass es tatsächlich zu einer Vergewaltigung gekommen war. Dies sollte sie durch Geschrei und Rufen um Hilfe tun. ${ }^{35}$ Beim Gericht sollte dann die betroffene Frau angemessene corpora delicti, insbesondere das verunreinigte oder beschädigte Kleid vorlegen. ${ }^{36}$ Die Ehre der vergewaltigten Jungfrau oder ehrenhaften Frau wurde vom Gericht gewahrt; die Jungfrau oder Frau durfte nicht später Beleidigungen ausgesetzt sein, weil sie ein Opfer der Vergewaltigung gewesen war. ${ }^{37}$ Die betroffene Frau konnte vor Gericht erklären, dass sie den freien $^{38}$ Mann, der sie vergewaltigt hatte, zum Ehemann nehmen würde. Das sollte ihr das Gericht ermöglichen. Der Täter war in solchem Falle nur durch (kurzfristige) Haft oder Geldbuße zu bestrafen, wobei diese Strafe als eine Maßnahme zum Schutze der Ehre der betroffenen Frau zu betrachten war. Die aus derart ge-

\footnotetext{
32 Ebd. 309 (Art. M. XXXI., Abs. II.).

${ }^{33}$ Ebd. 308 (Art. M. XXXI., Abs. I.).

${ }^{34}$ Nach MALÝ, Trestní právo 245, bei Koldín genossen Prostituierte und „unehrliche“ Frauen überhaupt keinen Rechtsschutz. Vgl. auch JIREČEK, Codex juris bohemici 310 (Art. M. XXXIII., Abs. II.).

${ }^{35}$ FRANCEK, Zločin a sex 110.

36 JIREČEK, Codex juris bohemici 309 (Art. M XXXII.).

${ }^{37}$ Ebd.

${ }^{38}$ Gemeint ist ein persönlich freier Mensch, d. h. kein Untertan (keineswegs ein unverheirateter Mensch, was der betreffende Täter aber wegen der festgesetzten Eventualität begreiflicherweise sein musste). Siehe unten Anm. 39.
}

schlossener Ehe entsprungenen Kinder sollten für als ehelich gezeugt gehalten werden. ${ }^{39}$

Die Vergewaltigung war bei den böhmischen städtischen Gerichten im 16. und zu Anfang des 17. Jahrhunderts keine häufig vorkommende Straftat.

In den ersten zwei Jahrzehnten des 16. Jahrhunderts kann man in Prag aufgrund der Nachrichten der sogenannten Alten böhmischen Chronik, das heißt einer narrativen Quelle, zwei Vergewaltigungsfälle registrieren. Im Jahre 1506 wurden zwei Knechte kastriert, weil sie in Prager Neustadt „ein altes Weib“ vergewaltigt hatten. ${ }^{40}$ Zehn Jahre später wurden vier Prager Handwerker gehängt, die ein Dienstmädchen überfallen und vergewaltigt hatten. ${ }^{41}$ Ich konnte sonst in der in Frage kommenden Zeit keinen anderen Fall ausfindig machen, in welchem die Täter der Vergewaltigung der Kastration unterworfen worden wären.

In Kuttenberg [Kutná Hora] kann man in den Jahren 1521-1571 nur fünf Fälle der Vergewaltigung ermitteln. ${ }^{42}$ In zwei Fällen, wo der Täter bloß die Vergewaltigung gestand, wurde die Todesstrafe durch Enthauptung verhängt. ${ }^{43}$

Nur in zwei Fällen findet man in den Pardubitzer Pechbüchern die Vergewaltigung einer erwachsenen Frau. Hier wurde jedes Mal die Todesstrafe durch Enthauptung ausgesprochen. ${ }^{44}$ Im ersten der genannten Fälle (1574) wurde der Täter der Vergewaltigung und des Diebstahls zu dieser Strafe mit ausdrücklichem Hinweis auf die Bestimmung Kap. XLI., Art. 1 des Rechts-

\footnotetext{
${ }^{39}$ JIREČEK, Codex juris bohemici 310 (Art. M. XXXVI.).

${ }^{40}$ PALACKÝ, Staří letopisové 233. Vgl. auch FranCEK, Zločin a sex 110.

${ }^{41}$ FRANCEK, Zločin a sex $110 f$.

42 BisingerovÁ, BISINGER, Kutnohorský manuál 17 (Nr. 3), 24 (Nr. 36), 40 (Nr. 123), 54 (Nr. 193) und 74 (Nr. 293).

${ }^{43}$ Ebd. 17 (Nr. 3) und 40 (Nr. 123).

${ }^{44}$ FRANCEK, Pardubické smolné knihy 271f.(Nr. 286), 278f. (Nr. 294) und 333 (Nr. 361).
} 
buchs von Brikcius' 45 verurteilt (d. h. für Notzucht $^{46}$ ). Im zweiten Fall (1583) wurde der Täter zur oben genannten Strafe verurteilt, auch ausdrücklich wegen Vergewaltigung (auf der Straße am hellichten Tage). Es handelte sich um nur versuchte Vergewaltigung. Der Täter gestand auch Diebstahl und Raub, wurde aber nur wegen des Sexualdelikts bestraft. ${ }^{47}$

\section{Vergewaltigung eines Kindes und sexueller Missbrauch}

Die Vergewaltigung eines Kindes (stuprum violentum infantis) (dieser Begriff beinhaltet auch das Verbrechen des sexuellen Missbrauchs) wurde im böhmischen Stadtrecht aus der Zeit vor Schlacht am Weißen Berge im Art. M. XXXIV. von Koldíns Gesetzbuch geregelt. ${ }^{48}$ Während der Täter bei einer einfachen Vergewaltigung (d. h. Vergewaltigung einer erwachsenen Frau) entweder mit Enthauptung durch das Schwert oder mit dem Einflechten ins Rad bestraft werden sollte, ${ }^{49}$ wurde im Falle der Vergewaltigung eines Kindes ein strengerer Vollzug der Todesstrafe bevorzugt, das heißt Einflechten ins Rad. ${ }^{50}$

Die Fälle der Vergewaltigung eines Kindes beziehungsweise des sexuellen Missbrauchs eines Kindes kann man bei den böhmischen Stadtgerichten im 16. und zu Anfang des 17. Jahrhunderts nur sehr sporadisch und in einzelnen Fällen registrieren.

Im Jahre 1513 wurde ein nicht genannter Mann aus Prager Neustadt enthauptet. Er hatte ein

\footnotetext{
${ }^{45}$ Koldín (wie Anm. 16) 308 (Art. M. XXX., Abs. II.).

${ }^{46}$ FRANCEK, Pardubické smolné knihy 271f. (Nr. 286).

${ }^{47}$ Ebd. 333 (Nr. 361).

${ }^{48}$ Koldín (wie Anm. 16) 310 (Art. XXXIV.). Siehe auch KREUZ, K projednávání 34; MALÝ, Trestní právo 245, insb. Anm. 234.

${ }^{49}$ Siehe oben Anm. 31.

${ }^{50}$ KREUZ, K projednávání 34.
}

kleines Mädchen vergewaltigt, das die Tat kaum überlebt hatte. ${ }^{51}$

1575 stand ein Untertan für die Vergewaltigung seiner kleinen Stieftochter vor dem Pardubitzer Stadtgericht. Der Täter wurde durch Enthauptung bestraft, obwohl er im betrunkenen $\mathrm{Zu}$ stand gehandelt hatte. Die Tat wurde überdies nicht vollendet, es blieb nur beim Versuch. Im Urteil wurde ausdrücklich konstatiert, dass dem Täter eigentlich die Strafe der Pfählung verdient hätte, weil er diese seine Schandtat am kleinen Kind und als Stiefvater verübt hatte. Die Strafe der Enthauptung mit dem Schwert sei ein Ausdruck der Gnade. ${ }^{52}$

Im Jahre 1593 gestand ein Mann beim peinlichen Verhör vor dem Stadtgericht in der nordböhmischen königlichen Stadt Louny den brutal ausgeführten sexuellen Missbrauch eines 16 Wochen alten Kindes weiblichen Geschlechts. ${ }^{53}$ Außerdem gab er auch zu, Sodomie in Gestalt Geschlechtsverkehrs mit einem Kalb und einer Sau begangen zu haben. Der Täter wurde zu einer verschärften Todesstrafe verurteilt. Zuerst wurde ihm die rechte Hand abgehauen, dann wurde er geradbrecht und enthauptet, sein Haupt und seine Hand an einer langen Stange befestigt und sein Körper verbrannt. ${ }^{54}$

Wenn das Opfer eines Sexualdelikts ein Kind war und wenn es andere spezifische Umstände gab - z. B. den Verdacht, dass ein Kind vergewaltigt worden war -, handelte es sich um Fälle, die sich in der Sicht der Stadtgerichte von der Beweisführung her offenbar als ziemlich kompliziert darstellten. Diese unklaren Fälle wurden wegen der komplizierten Beweisführung darüber hinaus bei den böhmischen Stadtgerichten

\footnotetext{
51 PALACKÝ, Staří letopisové 299.

52 FRANCEK, Pardubické smolné knihy 278f. (Nr. 294).

- Vgl. auch František OBERPFALCER (Hg.), Vyznání na mučidlech. 276-278; FRANCEK, Zločin a sex 112f.

${ }^{53}$ OBerpfalcer, Vyznání na mučidlech 279. Vgl. auch RoEDL, Smolné knihy města Loun 54 (Nr. 20).

${ }^{54}$ Oberpfalcer, Vyznání na mučidlech 279.
} 
im 16. und zu Anfang des 17. Jahrhunderts oft im Akkusationsverfahren (d. h. im Verfahren aufgrund einer Privatklage) verhandelt.

Auch in den Fällen, in denen die Beweislage (aus heutiger Sicht) wesentlich günstiger, sogar eindeutig erscheint, war es ziemlich kompliziert, eine Person für schuldig zu erklären, gegen die Klage erhoben wurde wegen sexuellem Missbrauch bzw. Vergewaltigung eines Kindes. Sehr detailliert tritt dies zutage in einem im Jahre 1541 verhandelten Fall vor dem Stadtgericht der Prager Altstadt. Beim genannten Gericht wurde der Prager Altstädter Bürger und bekannte Rechtsgelehrte Brikcius von Licsko der Vergewaltigung bzw. des sexuellen Missbrauchs der vierjährigen Tochter seiner ehemaligen Köchin angeklagt. Diese Handlung bezeichnete der anklagende Vertreter des Opfers als „,abscheuliche, häßliche und sodomitische Tat". ${ }^{.55}$ Das betroffene Kind wurde durch dazu ausgewählte ehrenhafte Frauen untersucht, die zu dem Schlusse kamen, dass das Kind zweifelsohne Opfer der den Gegenstand der Anklage bildenden Straftat geworden war und an intimen Stellen Verletzungen erlitten hatte. Außerdem beschuldigte der Vertreter der anklagenden Partei Brikcius, dass er vor dem Stadtschultheißen einige Beweise verborgen hätte. Brikcius sprach hingegen von einem Komplott gegen seine Person, und seine ehemalige Köchin bezeichnete er als eine unehrliche Frau. Das Prager Altstädter Gericht konnte sich angesichts dieser Situation nicht zur Anerkennung der Schuld von Brikcius durchringen. Dennoch konnte das Gericht offensichtlich beim gegebenem Stand der Dinge und weil eine Reihe von Indizien vorhanden war, Brikcius nicht ganz freisprechen. Das Gericht kam in seinem Urteil zum einem etwas gewundenen Schluss: Es stellte fest, dass das Mädchen tatsächlich zum Opfer der Straftat geworden sei, die Gegenstand der Anklage war. Als Täter

\footnotetext{
${ }^{55}$ KREUZ, K projednávání.
}

wurde immer nur Brikcius genannt. Es sei auch nicht bewiesen, dass sich das Mädchen in der fraglichen Zeit nicht im Hause des Angeklagten befunden hätte. Diesen Indizien zum Trotz wurde kein Schuldspruch verkündet, sondern Brikcius wurde unter Strafandrohung nur befohlen, innerhalb von zwei Wochen seine Unschuld mittels eines Reinigungseides unter Beweis zu stellen. ${ }^{56}$

\section{Bigamie}

Bigamie (Doppelehe) kommt in den böhmischen Ländern schon im 14. Jahrhundert im geschriebenen Stadtrecht vor, zunächst im Iglauer Recht, von wo es später in das Brünner Stadtrecht übernommen wurde. ${ }^{57}$ Die Bigamie galt als schwerwiegende Straftat und sollte mit Enthauptung bestraft werden. Täter dieses Delikts konnte nur der Mann werden, der seine Frau verließ und - solange sie noch lebte - eine andere Frau heiratete. ${ }^{58}$ Die kurze Bestimmung des Brünner Stadtrechts wurde auch in das Rechtsbuch des Brikcius von Licsko übernommen. ${ }^{59}$

Eine eingehendere Regulierung des Tatbestandes des Delikts der Bigamie, die sich auch auf Frauen bezog, brachte Koldíns Gesetzbuch. Hier wurde das in Frage kommende Delikt als Heirat eines der Eheleute während der Lebensdauer des anderen definiert. ${ }^{60}$ Der Mann sollte für Bigamie mit Enthauptung bestraft werden, die

\footnotetext{
${ }^{56}$ Ebd. 40f.

${ }^{57}$ FLODR, Brněnské městské právo 320, 476f. Zu den Verhältnissen in Südwestdeutschland: FRITZ, Geschichte der Sexualität 259, 285, 296.

${ }^{58}$ Ebd. 320; Ders., Právní kniha I. 309f. (Art. 483); II. 128f. (Art. 483).

${ }^{59}$ JIREČEK, M. Brikcího 242 (Kap. XLI., Art. II.).

${ }^{60}$ MALÝ, Trestní právo 233. Vgl. auch FRANCEK, Zločin a sex 92-96.
} 
Frau durch Enthauptung oder durch lebendig Begraben. ${ }^{61}$

In der Praxis der böhmischen Stadtgerichte im 16. und zu Anfang des 17. Jahrhunderts stellte die Bigamie im Vergleich mit anderen schweren sexuellen Delikten bzw. Delikten gegen die Ehe keineswegs eine so seltene Straftat dar, wie es in der Vergangenheit einige Forscher angenommen haben. ${ }^{62}$ Manche Fälle, die unter den Rechtsbegriff Bigamie fielen, wurden vor kirchlichen (das heißt in Böhmen im 16. und am Anfang des 17. Jahrhunderts konsistorialen) Gerichten statt vor weltlichen Instanzen verhandelt. ${ }^{63}$ Es ist auch zu bemerken, dass es in einigen konkreten Fällen relativ schwierig ist zu ermitteln, ob ein Mann oder eine Frau, die ihren Ehepartner verlassen hatten, sich stricto sensu der Bigamie schuldig machten, d. h. den neuen Partner ehelichten oder bloß eines Konkubinats ${ }^{64}$ oder wiederholten Ehebruchs. ${ }^{65}$

Trotz der eindeutigen Bestimmungen des Stadtrechts bestraften böhmische Stadtgerichte im 16 . und zu Anfang des 17. Jahrhunderts die Bigamie in der Regel meist recht milde, d. h. mit bedingter Todesstrafe, mit entehrenden Strafen am Pranger, mit körperlicher Bestrafung (Prügel), mit Brandmarken oder Verbannung. Nichtsdes-

${ }^{61}$ JIREČEK, Codex juris bohemici 311 (Art. M. XL., Abs. I.-II.). Vgl. auch MALÝ, Práva městská Království českého 277 (Art. M. XL., Abs. I.-II.).

${ }^{62}$ Typisch MALÝ, Trestní právo 233, inkl. Anm. 173, der mit Hinweis auf die einzige Eintragung im Kuttenberger Pechbuch schreibt, dass in der eigentlichen Gerichtspraxis die Frequenz der Bigamie sehr niedrig gewesen sein muss und die wirklich abgeurteilten oder bestraften Fälle selten erschienen. Diese Feststellung stellt leider eher eine Folge sehr beschränkten Erfassens der Quellen als eine glaubwürdige Bewertung damaliger Gerichtspraxis dar.

${ }^{63}$ MaLÝ, Trestní právo 233, inkl. Anm. 174. Vgl. auch FRANCEK, Zločin a sex 92-94.

${ }^{64}$ FRANCEK, Zločin a sex 92; DERS., Já jsem se dopustila 38.

${ }^{65}$ MaLÝ, Trestní právo 233, äußerte sogar die Meinung, dass in der Praxis die Delikte der Bigamie und des Ehebruchs oft zusammenfließen. toweniger begegnet man insbesondere im Laufe des 16. Jahrhunderts nicht selten auch Kapitalstrafen für die Täter der Bigamie, dies vor allem im Wiederholungsfalle oder im Falle des $\mathrm{Zu}$ sammenhangs mit anderen Straftaten, insbesondere mit Sitten- und Eigentumsdelikten. ${ }^{66}$

Im Jahre 1506 wurde in der ostböhmischen Stadt Trutnov wegen Bigamie der ehemalige Bürgermeister enthauptet, der dann schmählich bei der Friedhofswand begraben wurde. ${ }^{67}$

In Kutná Hora lassen sich anhand des Pechbuches allein in den Jahren 1552-1571 zehn Bigamiefälle verzeichnen, in denen insgesamt 14 Täter vor Gericht standen, davon überraschenderweise acht Frauen ${ }^{68}$ und bloß sechs Männer. ${ }^{69}$ Unter den in der fraglichen Zeit vom Kuttenberger Stadtgericht auferlegten Strafen für Bigamie überwog die Verbannung aus der Stadt, der meist Auspeitschung am Pranger vorausging. ${ }^{70}$ In zwei Fällen verurteilte aber das Kuttenberger Gericht zwei männliche Täter zum Tode durch das Schwert. ${ }^{71}$

Eine zweistellige Anzahl der Bigamietäter kann man auch anhand Pardubitzer Pechbücher feststellen. Beim Pardubitzer Halsgericht fielen in den Jahren 1555-1610 fünfzehn Fälle der Bigamie an, in denen 13 Männer ${ }^{72}$ und zwei Frauen ${ }^{73}$

\footnotetext{
${ }^{66}$ FRANCEK, Zločin a sex $94 \mathrm{f}$.

${ }^{67}$ WINTER, Kulturní obraz II. 776. Vgl. auch FRANCEK, Zločin a sex 95 .

${ }^{68}$ BISINGEROVÁ, BiSINGER, Kutnohorský manuál 33 (Nr. 87), 41 (Nr. 127), 62 (Nr. 233), 64 (Nr. 241), 67 (Nr. 258), 78 (Nr. 306), 78f. (Nr. 312), 81 (Nr. 324) und 114 (Nr. 8).

${ }^{69}$ Ebd. 33 (Nr. 87), 42 (Nr. 134), 61 (Nr. 226), 64 (Nr. 241), 65 (Nr. 244) und 78 (Nr. 306).

${ }^{70}$ Ebd. 33 (Nr. 87), 41 (Nr. 127), 62 (Nr. 233), 65 (Nr. 244), 67 (Nr. 258), 78 (Nr. 306), 78f. (Nr. 312), 81 (Nr. 324) und 114 (Nr. 8). Vgl. auch ObeRPFAlCER, Vyznání na mučidlech 269.

${ }^{71}$ BisingEROVÁ, BisingER, Kutnohorský manuál 42 (Nr. 134) und 65 (Nr. 244).

72 FrANCEK, Pardubické smolné knihy 165 (Nr. 116), 211f. (Nr. 175) 273f. (Nr. 288), 331 (Nr. 356), 357f. (Nr. 401), 392-395 (Nr. 442), 431f. (Nr. 466), $526 f$.
} 
geurteilt wurden. Die Männer, die keine schwerwiegendere Straftat bekannten, ${ }^{74}$ wurden hier meistens durch Enthauptung bestraft. ${ }^{75}$ Bei den Frauen tritt sowohl die durch Koldíns Gesetzbuch statuierte Strafe des Lebendigbegrabens $^{76}$ als auch bedeutend mildere Strafe vierwöchiger Haft ${ }^{77}$ in Erscheinung. ${ }^{78}$

\section{Inzest}

Das Delikt des Inzests (der Blutschande) ${ }^{79}$ wurde im Rahmen des böhmischen Strafrechts erst 1579 zum ersten Mal genau definiert, nämlich in

(Nr. 528), 536-539 (Nr. 536), 540-543 (Nr. 540), 556f. (Nr. 554) und 582 (Nr. 574).

${ }^{73}$ Ebd. 358 (Nr. 402) und 358f. (Nr. 403).

${ }^{74}$ Z.B. ebd. 273f. (Nr. 288): Todesstrafe durch Schleppen durch ein Pferd und Einflechten ins Rad wegen Mord; 431f. (Nr.466): Todesstrafe durch Erhängen wegen Diebstahl, mildernd in Enthauptung umgewandelt; 536-539 (Nr. 536): Todesstrafe durch Verbrennung wegen Brandstiftung.

${ }^{75}$ Ebd. 165 (Nr. 116), 211f. (Nr. 175), 392-395 (Nr. 442), 526f. (Nr. 528), 540-543 (Nr. 540) und 556f. (Nr. 554).

${ }^{76}$ Ebd. 358f. (Nr. 403).

77 Ebd. 358 (Nr. 402).

${ }^{78}$ Eine noch mildere Ahndung der Bigamie, als es einige Wochen im Gefängnis waren, kann man im Jahre 1570 in Prager Neustadt verzeichnen. Das dortige Stadtgericht entließ schließlich ohne ihn zu bestrafen auf Fürsprache von nicht genannten ehrbaren Bürgersfrauen einen Handwerker, der sich gerade der Bigamie schuldig gemacht hatte - Archiv hlavního města Prahy (Archiv der Hauptstadt Prag), Sbírka rukopisů (Handschriftensammlung), rukopis (Handschrift) Nr. 25, fol. 178v-179r. Vgl. auch WINTER, Kulturní obraz II, 776. Die Prager Eintragung zugleich bestätigt, dass die Klagen wegen Bigamie in der Zeit vor dem Weißen Berge auch beiden geistlichen Gerichten eingereicht wurden, die wie es scheint den überführten Täter dem weltlichen Gericht zur Verkündung der Strafe zu übergeben pflegten.

${ }^{79}$ Allgemein zur Problematik des Inzests, allerdings mit Schwerpunkt erst im 18. Jahrhundert, JARZEBOWSKI, Inzest; FRITZ, Geschichte der Sexualität 285.
Koldíns Stadtgesetzbuch, ${ }^{80}$ und zwar als Geschlechtsverkehr eines Mannes mit einer blutsverwandten Frau. ${ }^{81}$ Von Interesse ist, dass Koldín keine exakte Strafe für Inzest festsetzte, sondern bloß anordnete, dass es sich um eine strengere Strafe handeln sollte als die Strafe für Ehebruch, für den er allgemein eine nicht näher spezifizierte Art der Todesstrafe statuierte. ${ }^{82}$

Was die böhmischen im 16. und zu Anfang des 17. Jahrhunderts tätigen Stadtgerichte angeht, lassen sich nur einige vereinzelte Fälle von Inzest nachweisen. In der umfangreichen Agende des Pardubitzer Halsgerichts aus den Jahren 1538-1626 erscheint Inzest in einem einzigen Fall aus dem Jahre 1586. Damals bekannte ein gewisses Dienstmädchen, Unzucht mit ihrem eigenen Onkel getrieben zu haben und von ihm schwanger geworden zu sein. Der Onkel stand bei demselben Bauern als Knecht im Dienst und gestand die Unzucht, aus der die Schwangerschaft hervorgegangen war. Er bestritt aber, von der Verwandtschaft mit dem Mädchen etwas gewusst zu haben. Das Gericht stellte in seinem Urteil fest, dass im gegebenen Falle die Eheschließung für nicht genügenden Milderungsgrund respektive exkulpierenden Umstand gehalten werden kann. Den beiden Tätern wurde die Prügelstrafe und Herausführen aus der Stadt durch den Henker und Verbannung aus der Pardubitzer Herrschaft ",auf ewige Zeiten“ unter Androhung der Todesstrafe wegen Nichtbefolgung auferlegt. ${ }^{83}$

Im Jahre 1576 gestand vor dem Gericht der Stadt Broumov (dt. Braunau) Anna, Tochter von Nickel Treutler aus einem nahe gelegenen Dorfe, Mutter von drei unehelichen Kindern, Ehebruch mit einem Mann aus dem gleichen Dorfe. Von ihm war sie mit ihrem ersten Kind schwanger

\footnotetext{
${ }^{80}$ MALÝ, Trestní právo 245, inkl. Anm. 237; FrANCEK, Zločin a sex $114 \mathrm{f}$.

${ }^{81}$ JIREČEK, Codex juris bohemici 313 (Art. N. I.).

82 Ebd. 308 (Art. M. XXIX.).

${ }^{83}$ FRANCEK, Pardubické smolné knihy 366f. (Nr. 411).
} 
geworden. Außerdem gestand sie den Inzest mit ihrem eigenen Vater, mit welchem sie ihr zweites und drittes Kind hatte. Ihr Vater leitete sie darüber hinaus an, die Schuld an ihrer Schwangerschaft auf einen Vogler abzuwälzen, der sie manchmal besucht hatte. Außerdem sagte sie aus, intimen Verkehr mit ihrem Bruder Bartl gehabt zu haben. Der gestand, dass er auch mit der anderen (jüngsten) Schwester Eva fleischlichen Umgang gepflegt hätte. Eva bekräftigte dann in ihrer Aussage bloß, dass sie einige Jahre lang ein blutschänderisches Verhältnis mit ihrem Bruder gepflegt hatte. Alle drei Geschwister wurden wegen Inzest zum Feuertod verurteilt. Anna wurde darüber hinaus vor der Hinrichtung wegen verübten Ehebruchs auf dem Hauptplatz mit Gerten ausgepeitscht. ${ }^{84}$

\section{Sodomie - Geschlechtsverkehr mit einem Tier}

Der Geschlechtsverkehr mit einem Tier (Zoophilie) stellte bei den böhmischen Stadtgerichten im 16. und zu Anfang des 17. Jahrhunderts die am häufigsten verfolgte Form des Verbrechens der Sodomie dar. ${ }^{85}$ Man sollte vorausschicken, dass es sich hier um ein geschlechtsspezifisches, nämlich ausschließlich männliches Delikt handelte.

Es ist als eine Art Paradoxon zu betrachten, dass weder das aus den böhmischen Ländern stammende geschriebene Stadtrecht noch das geschriebene böhmische Strafrecht bis zum Anfang des 18. Jahrhunderts Bestimmungen hinsichtlich der Bestrafung des Geschlechtsverkehrs

\footnotetext{
${ }^{84}$ WeIsS, Braunauer Blutbuch 44f. Vgl. auch FRANCEK, Zločin a sex 115 .

${ }^{85}$ Allgemein zur historischen Entwicklung der Verfolgung der Sodomie in Gestalt des Geschlechtsverkehrs mit einem Tier LANG, Sodomie und Strafrecht 293ff. Vgl. zu allen Formen der Sodomie, also Sex mit Tieren, Homosexualität u. a. Formen der Sodomie: HEHENBERGER, Unkeusch wider die Natur., passim; ebenso: DABHOIWALA, Lust und Freiheit 153-164.
}

mit einem Tier enthält. ${ }^{86}$ Andererseits wies die bisherige Forschung darauf hin, dass in der Gerichtspraxis im 16. Jahrhundert der fleischliche Umgang mit einem Tier für ein schwerwiegendes Halsdelikt gehalten ${ }^{87}$ und streng bestraft wurde. ${ }^{88}$

In den Pardubitzer Pechbücher finden sich in den Jahren 1550-1607 sieben Fälle der Sodomie, ${ }^{89}$ außerdem ein Versuch, dieses Delikt zu verüben. ${ }^{90}$ Zum Objekt der geschlechtlichen Beziehung wurden am häufigsten eine Stute, ${ }^{91}$ aber auch eine Kuh oder eine Färse und Schafe. ${ }^{92}$ Die meisten Täter, die sich zur Sodomie mit einem Tier bekannt hatten, wurden zum Tode

${ }^{86}$ FLODR, Brněnské městské právo 319; MALÝ, Trestní právo 233; FRANCEK, Zločin a sex 115. Die erste Bestimmung über die Bestrafung des Geschlechtsverkehrs mit einem Tier findet sich in den Böhmischen Ländern erst mit der Peinlichen Gerichtsordnung Kaiser Josephs I. 1707; siehe z.B. FRANCEK, Zločin a sex $115 \mathrm{f}$.

${ }^{87}$ Das Pardubitzer Kriminalgericht berief sich in seinem Urteil aus dem Jahre 1586, in welchem auf Tod durch Verbrennung beim lebendigen Leib erkannt wurde, über den Täter der Sodomie mit drei Schafen, ausdrücklich auf das mosaische Recht, konkret den Dekalog (enthalten im 20. Kapitel des 2. Buchs Moses). Mit dem Übertreter sollten auch die Schafe verbrannt werden, die aber vorher getötet und ausgenommen werden sollten; siehe z. B. FRANCEK, Pardubické smolné knihy 375 .

${ }^{88}$ MALÝ, Trestní právo 233. Seine verallgemeinernde Behauptung, dass der Täter der Sodomie in Gestalt der Zoophilie mit dem Tier verbrannt wurde, das vorher getötet und ausgenommen worden war, stützt sich leider einerseits auf die Angaben der älteren Literatur (insbesondere WINTER, Kulturní obraz II, 782), andererseits auf die Belege anhand sehr schmaler und begrenzter Quellenbasis. Den einzigen Beleg über die vorhergehende Tötung des dann ausgenommenen Tieres enthält die oben in Anm. 87 zitierte Quelle.

${ }^{89}$ FrANCEK, Pardubické smolné knihy 131f. (Nr. 90), 198 (Nr. 155), 225 (Nr. 202), 374f. (Nr. 424), $529 f$. (Nr. 530), 555f. (Nr. 553) und 565-567 (Nr. 561).

${ }^{90}$ Ebd. 212 (Nr. 176).

${ }^{91}$ Ebd. 198 (Nr. 155), 225 (Nr. 202), 529 (Nr. 530), 555f. (Nr. 553) und 565-567 (Nr. 561).

${ }_{92}$ Ebd. 132 (Nr. 90), 212 (Nr. 176) und 374f. (Nr. 424). 
verurteilt und hingerichtet. Im ersten bekannten Falle aus dem Jahre 1550 zog das Pardubitzer Gericht die Strafe der Erhängung vor, wobei hier offenbar der Umstand berücksichtigt wurde, dass der Hauptteil der Delikte des Delinquenten aus Diebstählen bestand. ${ }^{93}$ In den 1560er Jahren ging das genannte Gericht zur Strafe der Enthauptung über. ${ }^{94}$ Ein einziges Mal kann man die Strafe der Verbrennung wegen Zoophilie feststellen, nämlich in Pardubice im Jahre 1586. Damals bekannte sich der Täter zum wiederholten Geschlechtsverkehr mit drei Schafen. ${ }^{95}$ Die letzten zwei registrierten Täter der Zoophilie wurden 1605 und 1608 enthauptet.96

Im Kuttenberger Pechbuch erscheint dagegen ein einziger Sodomie-Fall. Im Jahre 1568 war in Kutná Hora ein Mann wegen Geschlechtsverkehrs mit einer Kuh zur Prügelstrafe am Pranger und zum Aufbrennen von zwei Zeichen verurteilt und dann unter Androhung der Todesstrafe aus der Stadt verbannt worden. ${ }^{97}$

Im Jahre 1601 wurde in Mladá Boleslav (dt. Jungbunzlau) ein Untertan, der gestanden hatte, er habe "diese Tat [...] mit einem Vieh, einer Kuh nämlich verübt", mit der genannten Kuh zusammen verbrannt. ${ }^{98}$

Objekt von zoophilen Handlungen waren in den Fällen, die man bei den böhmischen Stadtgerichten im 16. und zu Anfang des 17. Jahrhunderts registrieren kann, ausnahmsweise Stuten, Kühe,

${ }^{93}$ Ebd. 132 (Nr. 90).

${ }^{94}$ Ebd. 198 (Nr. 155) und 225 (Nr. 202).

${ }^{95}$ Ebd. 375 (Nr. 424).

${ }^{96}$ Ebd. 556 (Nr. 553) und 567 (Nr. 561).

${ }^{97}$ BisingerOVÁ, Bisinger, Kutnohorský manuál 79 (Nr. 315).

98 Státní oblastní archiv v Praze (Staatsgebietsarchiv in Prag), pobočka Státní okresní archiv (Zweigstelle Staatsbezirksarchiv) Mladá Boleslav/Jungbunzlau, fond Archiv města Mladé Boleslavi (Archivfonds Archiv der Stadt Jungbunzlau), Sign. 958, fol. 51ㄴ-52r. Vgl. auch WINTER, Kulturní obraz II, 782.
Schafe und Sauen geworden, also die verbreitetsten großen Haustiere. ${ }^{99}$

\section{Sodomie - gleichgeschlechtlicher Verkehr (Homosexualität)}

Ähnlich wie im Falle des fleischlichen Umgangs mit einem Tier enthielten weder das geschriebene Stadtrecht in den böhmischen Ländern noch das geschriebene böhmische Strafrecht bis zum Anfang des 18. Jahrhunderts Bestimmungen bezüglich homosexuellen Geschlechtsverkehrs und seiner Bestrafung. ${ }^{100}$

Zum Unterschied vom fleischlichen Umgang mit einem Tier lässt sich in Böhmen im 16. und zu Anfang des 17. Jahrhunderts der Geschlechtsverkehr zwischen Personen gleichen Geschlechts nur ausnahmsweise erfassen. Trotzdem wird man konstatieren dürfen, dass es sich damals was das Geschlecht betrifft, um ein spezifisches Männerdelikt handelte. Die Fälle des homosexuellen Verkehrs zwischen Frauen lassen sich in der fraglichen Zeit in Böhmen überhaupt nicht verzeichnen - ausgenommen den Fall, dass sich eine der betreffenden Frauen dabei für einen Mann ausgab. ${ }^{101}$

Dem einzigen Fall gerichtlicher Strafverfolgung eines Täters der Homosexualität im Böhmen vor der Schlacht am Weißen Berge begegnet man nicht in einer Quelle gerichtlicher Provenienz, sondern in einer erzählenden: In seinen Erinnerungen erwähnt der Kuttenberger nobilitierte

\footnotetext{
${ }^{99}$ FRANCEK, Zločin a sex 116, führt neben ihnen als ein Objekt der Sodomie auch Hündinnen an. Die zoophile Beziehung mit einer Hündin konnte ich aber im untersuchten Material nicht verzeichnen.

100 Vgl. oben Anm. 86. Zur Homosexualität vom 10.19. Jahrhundert auch: FRITZ, Geschichte der Sexualität 286-289; zu mittelalterlichen Fällen: HERGEMÖLLER, Fontes sodomitarum.; NAPHY, Verbotene Leidenschaft 78. Naphy weist darauf hin, dass sogar im calvinistischen Genf Homosexualität recht häufig vorkam. ${ }^{101}$ Siehe unten Anm. 103 und 104.
} 
Bürger Mikuláš Dačický von Heslov (1555-1626) folgenden Vorfall: Im Jahre 1590 erlitt den Feuertod bei lebendigem Leibe in Žehušice (dt. Sehuschitz) bei Kutná Hora der junge Lehrer Sixtus, der mit Gewalt seine Schüler zu homosexuellem Verkehr genötigt hatte. Der betreffende Lehrer wurde aber nicht vom Stadtgericht abgeurteilt. Die Handlungsweise des Lehrers bezeichnete Dačický mit den Worten „italienische Sodomiterei“ (vlaské sodomství). Überhaupt galt im 15./16. Jahrhundert Homosexualität auch außerhalb von Böhmen in anderen Gegenden des Reiches dermaßen als italienisches, speziell florentinisches Delikt, dass das damals neu entstandene Verb „florenzen“ für homosexuellen Verkehr weit verbreitet war. ${ }^{102}$

\section{Andere Formen der Sodomie}

In diesem Kapitel möchte ich mich zuerst anderen (wirklichen oder vermeintlichen) Äußerungen der sexuellen Orientierung widmen, vor allem dem Transvestitismus, der Transsexualität, der Nekrophilie und dem Exhibitionismus in Böhmen im 16. und zu Anfang des 17. Jahrhunderts. Ich werde auch die Frage nach der Beziehung der heterosexuellen Praktiken, die nicht direkt zur Empfängnis führten, zum Delikt der Sodomie, berühren.

In den böhmischen Städten ist, was die Zeit vor der Schlacht am Weißen Berge angeht, nur ein einziger Fall weiblicher Transsexualität verzeichnet. Der in Frage kommende Vorfall ereignete sich zwar im Jahre 1590 in Mladá Boleslav, ist aber in der Saazer Stadtchronik überliefert,

102 MiKUleC, Mikuláš Dačický 138f; Zum genannten Fall siehe auch Winter, Kulturní obraz II, 639; FRANCEK, Zločin a sex 117; HIML, Proti přirozenosti 23 und 56; Zum Begriff „florenzen“ und zum gesamten Sachverhalt der Homosexualität: FRITZ, Geschichte der Sexualität 286-289, und KARRAS, Sexualität im Mittelalter 290ff. also nur in einer erzählenden Quelle. ${ }^{103}$ Es geht um folgenden Fall: Eine Dienstmagd, die sich als Knecht ausgegeben hatte, hatte sich nach dem Tode ihres Wirts und ihrer Wirtin mit deren verwaister Tochter verheiratet. Die betrogene Braut hatte die wahre Identität ihres „Ehegatten" erst einige Woche nach der Heirat festgestellt. Die Täterin wurde dann zum Tode verurteilt und bei lebendigem Leib begraben. ${ }^{104}$

Im Jahre 1567 bekannte in Kutná Hora ein Bäckergeselle, dass er drei Jahre lang in Frauenkleidern gegangen sei. Obwohl er früher wegen Herumgehens in diesen Kleidern aus der westböhmischen königlichen Stadt Domažlice (dt. Taus) verwiesen worden war, handelte es sich bei diesem Täter offensichtlich nicht um eine Äußerung des Transvestitismus oder der Transsexualität, sondern um ein Mittel, die Dienstmädchen um ihre Jungfräulichkeit zu bringen. Der betreffende Geselle wurde schließlich wegen zahlreicher Diebstähle und Unzucht zum Tode mit dem Strang verurteilt. ${ }^{105}$ Ebenfalls des Transvestitismus bediente sich ein Knecht, der in der Prager Altstadt im Jahre 1504 erwischt und gerichtet wurde. Dort hatte er sich als eine Köchin ausgegeben und bei einer Bürgersfrau im Dienst gestanden, zu der er auch freien $\mathrm{Zu}$ tritt gehabt hatte. Der Knecht wurde nur mit einer entehrenden und körperlichen Strafe gezüchtigt - mit einer harten Verprügelung bzw. Auspeitschung. Die betreffende Bürgersfrau hatte eine Geldbuße zu bezahlen. ${ }^{106}$

\footnotetext{
103 TOŠNEROVÁ, Paměti města Žatce 25f.

${ }^{104}$ Ebd.; FranCEK, Zločin a sex 69; KREUZ, K projednávání 33f., Anm. 3. Ein Beispiel zu einem Transvestiten in der Chronik der Grafen von Zimmern (vgl. den Beitrag von Gerhard Fritz im vorliegenden Band) ist erläutert bei FRITZ, Geschichte der Sexualität 293.

${ }^{105}$ OBerpfalcer, Vyznání na mučidlech 267f. Vgl. auch BISINGEROVÁ, BISINGER, Kutnohorský manuál 74 (Nr. 293).

106 PALACKÝ, Staří letopisové 225 (Nr. 710).
} 
Nicht als eine Äußerung der Transsexualität, des Transvestitismus, beziehungsweise einer anderen sexuellen Minderheitsorientierung, kann man Situationen ansprechen, in denen sich Frauen beim Vollzug bestimmter (damals) ausgesprochen männlicher Berufe oder in ihrem Bestreben ein höheres gesellschaftliches Prestige zu erreichen, als Männer ausgaben. Dies berührte ausnahmsweise auch gewalttätige Straftaten mit deutlicher maskuliner Genderrelation. ${ }^{107}$ Vielleicht mit Ausnahme des oben genannten Jungbunzlauer Vorfalls aus dem Jahre $1590^{108}$ wurde im frühneuzeitlichen Böhmen bisher kein Fall registriert, dass sich eine lesbische Frau als Mann ausgab, um zu einer intimen Beziehung, eventuell $\mathrm{zu}$ einem ehelichen Bund mit einer Angehörigen ihres Geschlechts zu kommen.

In der zweiten Hälfte des 16. und im ersten Drittel des 17. Jahrhunderts kann man in den Eintragungen über die vor den böhmischen Stadtgerichten verhandelte Straftaten keinen Fall der Nekrophilie verzeichnen.

Was den Exhibitionismus (öffentliches EntblöBen) anbelangt, ist bis jetzt aus den böhmischen Stadtgerichten nur eine einzige Nennung aus der Zeit vor dem Weißen Berge bekannt. Es wird lediglich ausgesagt, dass das Enthüllen des Geschlechtsglieds vor den Augen anderer Personen allgemein für Sodomie gehalten wurde. ${ }^{109}$ In der böhmischen, überwiegend tschechisch geschriebenen sittenlehrenden Literatur aus der Zeit vor dem Weißen Berge wurden als Sodomie (sodomitische Unzucht) auch andere, meistens heterosexuelle Praktiken bezeichnet, die nicht

107 Zum Beispiel OBERPFALCER, Vyznání na mučidlech 276.

108 Siehe oben Anm. 103 und 104.

109 MALÝ, Trestní právo 246, Anm. 242 führt den Fall eines Prager Neustädter Bürgers an, der im Gefängnis sein Geschlechtsglied vor anderen Eingekerkerten „,auf sodomitische Art“ enthüllte. Zu demselben Fall Národní archiv v Praze (Nationalarchiv in Prag), fond Apelační soud (Archivfonds Appellationsgericht), Inventarnummer 101, fol. 32 $-33^{\mathrm{v}}$. direkt zu Empfängnis führten wie Onanie, Analund Oralsex und sogar unnatürliche Lagen beim Beischlaf. ${ }^{110}$

\section{Schluss}

Die hier beschriebenen schweren Sexualdelikte wurden im 16. und zu Anfang des 17. Jahrhunderts nicht allzu oft vor den böhmischen Stadtgerichten verhandelt. Unter einigen Tausend kriminellen Fällen, die man bei den genannten Gerichten in den auf uns gekommenen Quellen registrieren kann, handelt es sich in der Summe bloß um einige Dutzend (also nicht um Hunderte) Fälle. Neben Delikten, die in relativ höherer Zahl erscheinen (Bigamie, Sodomie in Gestalt des sexuellen Verkehrs mit einem Tier, Vergewaltigung) kommen manche von diesen Delikten entweder sporadisch (Inzest) oder überhaupt nur in ganz vereinzelten spezifischen Fällen vor (Homosexualität, Vergewaltigung eines Kindes bzw. sein sexueller Missbrauch, Transsexualität, Exhibitionismus). Das relativ häufiger in Erscheinung tretende Delikt der Entführung, respektive des Weglockens der Ehefrau nahm dann im realen Leben und in der Gerichtspraxis sehr mannigfaltige und von der ursprünglichen Absicht des Gesetzgebers offensichtlich ziemlich abweichende Formen an.

$\mathrm{Zu}$ allgemeineren Schlussfolgerungen hinsichtlich der Strafverfolgung von schweren sexuellen Delikten in der Gerichtspraxis der böhmischen Städte im 16. und zu Anfang des 17. Jahrhunderts kann man nur bei jenen Delikten kommen, die man in höherer Zahl erfassen kann. Die strengsten für diese Delikte auferlegten Strafen waren durch ihre Härte den im damaligen Recht statuierten, d. h. in der Regel Kapitalstrafen gleich. (In der Praxis handelte es sich also um eine obere Grenze des Strafsatzes.) In den meisten Fällen wurden aber (entweder gleich oder

${ }^{110}$ FRANCEK, Zločin a sex 116. 
auf dem Wege der Gnade) mildere Strafen auferlegt. Eine gewisse Verschärfung der von böhmischen Stadtgerichten auferlegten Strafen lässt sich in den letzten Dezennien des 16. und zu Anfang des 17. Jahrhunderts bei einigen sexuellen Delikten beobachten. Trotzdem ist es möglich zu konstatieren, dass in der in Frage kommenden Zeit die städtische Gerichtspraxis in Böhmen bei der Verfolgung schwerer sexueller Delikte in den meisten Fällen und manchmal ziemlich ausdrucksvoll vom damals geltenden Recht abwich, und zwar in der Regel zugunsten des Täters. Mehr als im Falle der anderen Delikte (z. B. Eigentumsdelikten) war die Verfolgung schwerer Delikte im sexuellen Bereich beeinflusst von konkreten sozialen und andere zeitspezifischen Umständen. Welche es sein konnten, habe ich wenigstens zum Teil in meinem Beitrag aufzuzeigen versucht.

\section{Korrespondenz:}

Doz. Dr. Petr KREUZ

Archiv hlavního města Prahy

Archivní 6

14700 Praha 4

Česká republika

petr.kreuz@praha.eu

ORCID-Nr. 0000-0001-7484-4773

\section{Abkürzungen:}

Siehe das allgemeine Abkürzungsverzeichnis: [http://www.rechtsgeschichte.at/files/abk.pdf]

\section{Literatur:}

Marie BisingerovÁ, Zdeněk Bisinger (Hgg.), Kutnohorský manuál práva útrpného (smolná kniha) 1521-1571 (Kuttenberg 1987).

Jaromír ČELAKOVSKÝ, O právech městských m. Brikcího z Licska a o poměru jich k starším sbírkám právním, in: Časopis Musea Království českého 54 (1880) 721-736, 757-774, 794-808 und 829-837.

Faramerz DABHOIWALA, Lust und Freiheit. Die Geschichte der ersten sexuellen Revolution. Aus dem Englischen von Esther und Hainer Kober (Stuttgart 2014).

Miroslav FlodR (Hg.), Právní kniha města Brna z poloviny 14. století, 3 Bde. (Brno 1990/1993).

Miroslav FLODR, Brněnské městské právo (Brno 2001).

Jindřich FRANCEK, Zločin a sex v českých dějinách raného novověku (Prag 2000).

Jindřich FRANCEK, Já jsem se dopustila... Sexuální delikty ve východních Čechách 16.-18. století (Ústí nad Orlicí 2008).

Jindřich FRANCEK (Hg.), Pardubické smolné knihy 1538-1626, Teil 1-2 (Pardubice 2016).

Gerhard FRITZ, Geschichte der Sexualität von den Anfängen bis zur Gegenwart. Südwestdeutschland und seine Nachbargebiete (Ubstadt-Weiher 2016)

Susanne HEHENBERGER, Unkeusch wider die Natur. Sodomieprozesse im frühneuzeitlichen Österreich (Wien 2006).

Bernd-Ulrich HERGEMÖLLER (Hg.), Fontes sodomitarum. Ausgewählte Quellen zur Homosexuellenverfolgung im christlichen Mittelalter (Hamburg 2013).

Pavel HimL, Proti přirozenosti. Stejnopohlavní vztahy v předmoderních dějinách českých zemí, in: DERS., Jan SEIDL, Franz ScHINDLER (Hgg.), „Miluji tvory svého pohlaví." Homosexualita v dějinách a společnosti českých zemí (Prag 2013) 23-75.

Claudia JARZEBOWSKI, Inzest. Verwandtschaft und Sexualität im 18. Jahrhundert (Köln-Weimar 2006).

Josef JIREČEK, Hermenegild JIREČEK (Hgg.), M. Brikcího z Licska Práva městská (Prag 1880). 
Josef JIREČEK (Hg.), Codex juris bohemici. Tomi IV. pars III. Monumenta juris municipalis. Sectio II., exhibens Mag. Pauli Christiani a Koldín Jus munici-pale regni Bohemiae una cum compendio ejusdem juris (Pragae 1876).

Ruth Mazo KARRAS, Sexualität im Mittelalter (Düsseldorf 2006).

Petr KREUZ, K projednávání deliktu pohlavního zneužití a znásilnění dítěte před městským soudem $\mathrm{v}$ předbělohorských Čechách (zároveň příspěvek k životopisu Mistra Brikcího Kouřimského z Licska), in: Nardi aristae. Sborník k sedmdesátým narozeninám Ivana Martinovského (Aussig 2007) 33-58.

Petr KREUZ, Stav a perspektivy vydávání smolných knih a př́buzných pramenů $\mathrm{k}$ dějinám hrdelního soudnictví v českých zemích, in: Michaela HRUBÁ, Ludmila SuliTKOVÁ, Vilém ZÁBRANSKÝ (Hgg.), Stav a perspektivy zpřístupňování středověkých a raně novověkých městských knih (Aussig 2010) 213-240.

Dominik LANG, Sodomie und Strafrecht. Geschichte der Strafbarkeit des Geschlechtsverkehrs mit Tieren (Frankfurt am Main-Berlin-Bern-BruxellesNew York-Oxford-Wien 2009).

Karel MALÝ, Trestní právo v Čechách 15.-16. století (Prag 21989).
DERs. u.a. (Hgg.), Práva městská Království českého. Edice s komentářem (Prag 2013).

Jiří MikUlec (Hg.), Mikuláš Dačický z Heslova, Paměti (Prag 1996).

William NAPHY, Verbotene Leidenschaft. Gesellschaft und Sexualität von der Renaissance zur Aufklärung (Essen 2003).

František OBERPFALCER (Hg.), Vyznání na mučidlech. Texty ze starých knih černých, jinak smolných (Praha 1937).

František PALACKÝ (Hg.), Staří letopisové čeští od roku 1378 do 1527 čili pokračování v kronikách Přibíka Pulkavy a Beneše $\mathrm{z}$ Hořovic z rukopisů starých vydané, in: Jaroslav CHARVÁt (Hg.), Dílo Františka Palackého, Bd. 2 (Prag 1941).

Bohuslav RoučKA, Poznámky k mapě hrdelních soudů v Čechách v první a ve druhé polovině 18 . století, in: Právněhistorické studie 3 (1957) 115135.

Marie ToŠnEROVÁ (Hg.), Paměti města Žatce 15271609 (Saaz 1996).

Franz WEISS (Hg.), Das Braunauer Blutbuch. Das „Register über die peinlichen Fragen 1550" der Stadt Braunau in Böhmen (Hohenelbe 1927).

Zikmund WINTER, Kulturní obraz českých měst. Život veřejný v XV. a XVI. věku. 2. Band (Praha 1892). 